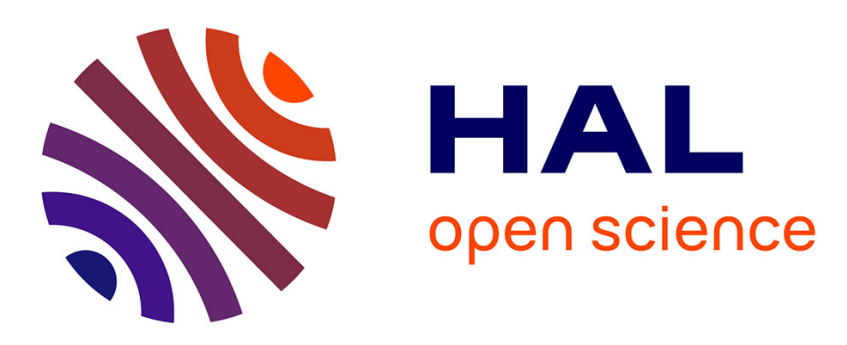

\title{
Lanthanide Isophthalate Metal-Organic Frameworks: Crystal Structure, Thermal Behavior, and White Luminescence
}

Virgile Trannoy, Isis N'Dala-Louika, Jérôme Lhoste, Thomas Devic, Hélène Serier-Brault

\section{To cite this version:}

Virgile Trannoy, Isis N'Dala-Louika, Jérôme Lhoste, Thomas Devic, Hélène Serier-Brault. Lanthanide Isophthalate Metal-Organic Frameworks: Crystal Structure, Thermal Behavior, and White Luminescence. European Journal of Inorganic Chemistry, 2021, 2021 (4), pp.398-404. 10.1002/ejic.202000906 . hal-03275267

\section{HAL Id: hal-03275267 https://hal.science/hal-03275267}

Submitted on 30 Jun 2021

HAL is a multi-disciplinary open access archive for the deposit and dissemination of scientific research documents, whether they are published or not. The documents may come from teaching and research institutions in France or abroad, or from public or private research centers.
L'archive ouverte pluridisciplinaire HAL, est destinée au dépôt et à la diffusion de documents scientifiques de niveau recherche, publiés ou non, émanant des établissements d'enseignement et de recherche français ou étrangers, des laboratoires publics ou privés. 


\section{Lanthanide isophthalate metal-organic frameworks:}

\section{crystal structure, thermal behavior and white}

\section{luminescence properties}

Virgile Trannoy ${ }^{* \dagger}$, Isis N’Dala-Louika ${ }^{\dagger}$, Jérôme Lhoste ${ }^{ \pm}$, Thomas Devic ${ }^{\dagger}$, Hélène Serier-Brault ${ }^{*},+$

† Dr. V. Trannoy, Ms. I. N’Dala-Louika, Dr. T. Devic, Dr. H. Serier-Brault

Université de Nantes, CNRS, Institut des Matériaux Jean Rouxel, IMN, F-44000 Nantes, France.

\pm Dr. J. Lhoste

Université du Maine, Institut des Molécules et Matériaux du Mans, UMR CNRS 6283, Avenue

Olivier Messiaen, 72085 Le Mans, France.

\section{Corresponding Author}

helene.brault@cnrs-imn.fr htps://www.cnrs-imn.fr/index.php/accueil-l-imn/annuaireimn-membres-de-l-imn-par-noms-et-par-services/item/brault-helene

Twitter : @brault_helene

virgile.trannoy@lspm.cnrs.fr $\quad$ https://www.researchgate.net/profile/Virgile_Trannoy

Twitter : @VTrannoy 


\section{Supporting Information.}

PXRD, FT-IR, TGA, thermodiffraction analyses, lattice parameters evolution with the temperature, PL spectra and CIE diagram and some crystal parameters (PDF).

ABSTRACT Two novel lanthanide metal-organic frameworks (LnMOFs), $\mathrm{Ln}_{1.14} \mathrm{Na}_{0.57}(\mathrm{BDC})_{2}\left(\mathrm{H}_{2} \mathrm{O}\right) \cdot 4 \mathrm{H}_{2} \mathrm{O}\left(\mathrm{Ln}=\mathrm{La}^{3+}\right.$ or $\mathrm{Ce}^{3+}$, BDC : 1,3-benzenedicarboxylate), have been synthesized under hydrothermal conditions by using a $\mathrm{Ln}^{3+}$ coordination polymer as precursor. The crystal structure was determined from single crystal X-ray diffraction. Both compounds are isostructural and contain chains of face-sharing $\left[\mathrm{LnO}_{10}\right]$ polyhedra connected by the linkers to form an anionic three-dimensional network, defining both polar and apolar channels, the latter being occupied by water molecules and $\mathrm{Ln}^{3+}$ and $\mathrm{Na}^{+}$cations. When doped by optimized content of $\mathrm{Eu}^{3+}$ and $\mathrm{Tb}^{3+}$, the $\mathrm{La}^{3+}$ counterpart exhibits white luminescence emission with CIE parameters equal to $(0.3440,0.3735)$ at $\lambda_{\text {exc }}=321 \mathrm{~nm}$, which renders the material attractive for white LED application.

\section{INTRODUCTION}

Lanthanide-based MOFs (LnMOFs) are considered as promising functional materials for optical properties, especially due their luminescent properties that can be used for applications such as chemical or temperature sensing, lightings, displays ${ }^{[1-8]} \ldots$ Recently, LnMOFs have attracted increasing attention in the active field of single-phase white light emission materials ${ }^{[9-}$ 18]. Compared to the inorganic phosphors, LnMOFs compounds offer many advantages for the elaboration of new single-phase phosphors such as their slow temperature synthesis, the efficient antenna effect of the ligand, and the ease to homogenously co-dope by $\mathrm{Ln}^{3+}$ cation to generate 
various emission colors ${ }^{[19]}$. To conceive a single-phase white-luminescent MOF material, a promising approach consists in tuning the proportion of the blue emission of the organic ligand, the green light from $\mathrm{Tb}^{3+}$ cation and the red color from $\mathrm{Eu}^{3+}$ cation ${ }^{[11,13-18,20-26]}$. The tuning of relative proportion of each color can be optimized by adjusting the different amounts of the red and green emitters, but also by an adjustment of the excitation wavelength in order to modulate the blue emission of the ligand and obtain the required white emission ${ }^{[12,20]}$.

For an efficient energy transfer from an organic linker to $\mathrm{Eu}^{3+}$ and $\mathrm{Tb}^{3+}$ ions, the ligand should have suitable triplet excited-state energy (between 22000 and $27000 \mathrm{~cm}^{-1}$ ) matching the energy of the main accepting levels of $\mathrm{Eu}^{3+}\left({ }^{5} \mathrm{D}_{1}: 19030 \mathrm{~cm}^{-1}\right)$ and $\mathrm{Tb}^{3+}\left({ }^{5} \mathrm{D}_{4}: 20500 \mathrm{~cm}^{-1}\right)^{[3]}$. In this purpose, aromatic carboxylate acids are usually chosen as photosensitizers to construct the LnMOFs compounds. Targeting an application such as white LED lightening, efforts must be done to develop efficient materials with a relative low synthesis cost. In this context, we focus our attention on an inexpensive commercially available organic ligand, namely 1,3-benzenedicarboxylic acid, or isophthalic acid. This common linker is a rigid carboxylate ligand which enables various coordination modes to build MOF network ${ }^{[27-31]}$, and which gets an appropriate triplet excitedstate energy $\left(27900 \mathrm{~cm}^{-1}\right) \cdot{ }^{[32]}$ Herein, we report the synthesis of two new isomorphous 3D lanthanide-bearing metal-organic frameworks built up from isophthalate (1,3-BDC), with the chemical composition $\mathrm{Ln}_{1.14} \mathrm{Na} 0.57(\mathrm{BDC})_{2}\left(\mathrm{H}_{2} \mathrm{O}\right) \cdot 4 \mathrm{H}_{2} \mathrm{O}\left(\mathrm{Ln}=\mathrm{La}^{3+}\right.$ or $\left.\mathrm{Ce}^{3+}\right)$. The crystal structure of both compounds was determined by single-crystal X-ray diffraction, while their thermal behavior was investigated by multiple techniques (TGA, IR spectroscopy, temperature-dependent XRD). Additionally, we successfully obtained a luminescent material with white light emission by codoping the $\mathrm{La}^{3+}$ counterpart with $\mathrm{Tb}^{3+}$ and $\mathrm{Eu}^{3+}$ ions in appropriate proportions. 


\section{RESULTS AND DISCUSSION}

\section{Synthesis of the LnMOF}

During the synthesis and before the hydrothermal treatment, the addition under stirring of the $\mathrm{Ln}^{3+}$ salt into the limpid basic solution of the ligand leads to the formation of a white precipitate at $\mathrm{pH}=5$ and at room-temperature. The as-synthesized white powder obtained for $\mathrm{La}^{3+}$ and $\mathrm{Ce}^{3+}$ (La-CP and Ce-CP) were analyzed by PXRD, FTIR analysis and thermal analysis (Figures S1S3). Firstly, the X-ray diffraction patterns (Figure S1) is identical to that of a cerium benzene-1,3dicarboxylate compound reported by Zheng et al. ${ }^{[33]}$, and which was obtained by the reaction of of a $\mathrm{Ce}\left(\mathrm{NO}_{3}\right)_{3}$ aqueous solution with a solution a 4:1 ethanol-water solution of $\mathrm{H}_{2} \mathrm{BDC}$ at a $\mathrm{pH}=$ 7 (the $\mathrm{pH}$ being adjusted by the addition of ammonia solution). However, the crystal structure is unknown so far and a thorough search in the crystal structure database did not result in a convincing match. Nevertheless, efforts have been done to characterize this phase. Then, the FTIR spectroscopy (Figure S2) confirms the presence of solely deprotonated carboxylate groups (no band at ca. $1700 \mathrm{~cm}^{-1}$, characteristic of free carboxylic groups), while the TGA analysis (Figure S3) shows at $100^{\circ} \mathrm{C}$ a first mass loss of $22.7 \%$, and $23.5 \%$ for La-CP and Ce-CP, respectively, which can be attributed to the loss of water molecules. Moreover, complementary EDX measurements revealed the presence of sodium in the compounds with a cationic molar ratio $\mathrm{Ln} / \mathrm{Na}$ $(\mathrm{Ln}=\mathrm{Ce}$ or $\mathrm{La})$ equal to 5 , the sodium coming from the sodium hydroxide solution used to deprotonate the carboxylic acid. Additional elemental analyses confirmed a content of 29.35\%, 3.721\%, for $\mathrm{C}$ and $\mathrm{H}$, respectively, in La-CP, and a content of 29.35\%, 3.61\%, for C and H,

respectively, in $\mathbf{C e - C P}$, enabling to propose the molecular formula $\mathrm{Ln}_{0.938} \mathrm{Na}_{0.187}\left(\mathrm{C}_{8} \mathrm{H}_{4} \mathrm{O}_{4}\right)_{1.5} \cdot 6 \mathrm{H}_{2} \mathrm{O}$. 
Under hydrothermal conditions (see experimental part), both coordination polymers, namely LaCP and Ce-CP, are transformed to small colorless single-crystals suitable for single crystal XRD analysis. LaMOF and CeMOF, which are isostructural. Hence, only the structure of the La counterpart is described in detail. The compound crystallizes in the tetragonal apolar space group $P 4_{2} 2_{1} 2$. In the network, each $\mathrm{La}(1)$ cation is coordinated by ten oxygen atoms, eight oxygen atoms arising from the two different carboxylate groups and two oxygen atoms from water molecules in a distorted bicapped square prismatic environment (Figure 1a). The $\mathrm{La}(1) \cdots \mathrm{O}$ bond distances range from 2.473(5) to 2.686(4) (2.452(6) to 2.710(11) pour CeMOF) $\AA$ for a bond valence equal to 3.18 for $\mathrm{La}^{3+}$ cation (and 3.15 for $\mathrm{Ce}^{3+}$ cation) (Table S3). In the structure, only one coordination mode exists, namely monodentate/tridentate-chelating-bridging (Figure S5), as confirmed by the FTIR spectroscopic analysis: while the $\mathrm{C}=\mathrm{O}$ vibration band at $1693 \mathrm{~cm}^{-1}$ characteristic free carboxylic group in $\mathrm{H}_{2} \mathrm{BDC}$ vanished, a shoulder at ca. $1680 \mathrm{~cm}^{-1}$ associated with the dangling $\mathrm{C}=\mathrm{O}$ bond is detected (Figure S4) ${ }^{[34]}$. The coordination $\mathrm{La}(1) \mathrm{O}_{10}$ polyhedra are connected by a triangular face along the $c$ axis to form infinite chains. Subsequently, each chain is linked to four others chains by the $\mathrm{BDC}^{2-}$ ligand with a distance between metal centers equal to 11.231(1) along the $a$ axis $\AA$ (11.197(2) pour CeMOF) (Figure 1b) to form a 3D MOF network with channels running along the $c$ axis. The network exhibits alternating apolar and polar channels, the latter being occupied by disordered $\mathrm{Ln}^{3+}$ and $\mathrm{Na}^{+}$cations surrounded by water molecules to provide a final chemical composition of $\mathrm{La}_{1.14} \mathrm{Na}_{0.57}(\mathrm{BDC})_{2}\left(\mathrm{H}_{2} \mathrm{O}\right) \cdot 4 \mathrm{H}_{2} \mathrm{O}$. The presence of $\mathrm{Na}^{+}$cations was not expected and can be justified by the use of $\mathrm{NaOH}$ solution to dissolve and deprotonate the carboxylic acid during the synthetic process. The chemical composition was confirmed by elemental and thermal analyses, with a La/Na molar ratio increased to 2 after the hydrothermal process, while the number of water molecules represent $15.9 \%$ and $15.1 \%$ for LaMOF and 
CeMOF, respectively (Figure S6). The comparison of the experimental powder XRD pattern of both MOFs with that calculated from the determined structure (Figure S7) confirms that both compounds were prepared as pure phases. Furthermore, distances between the non-coordinated oxygen atom from the carboxylate ligand and the coordinated water molecule $\mathrm{O}_{\mathrm{w} 1}$ is equal to 2.699(9) $\AA$ (and 2.692(8) $\AA$ for CeMOF), indicating the presence of an hydrogen bond ${ }^{[35]}$ (Figure 1c).

a)
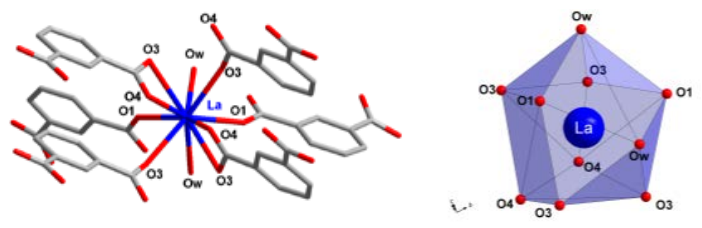

b)

c)

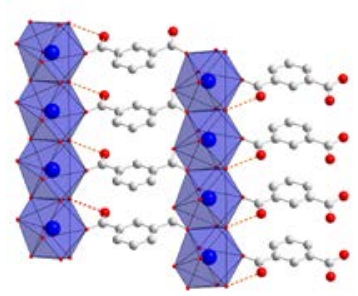

Figure 1. a) The coordination sphere of La in LaMOF forming a distorted bicapped square prism, b) Projection along the $c$ axis of the LaMOF structure (blue: $\mathrm{LaO}_{10}$ polyhedra, red: oxygen, yellow: sodium, grey: carbon, $\mathrm{H}$ atoms being omitted for clarity), c) H-bond (dotted red line) between the non-coordinated oxygen atom of the organic linker and the oxygen atom of the coordinated water molecule $\left(\mathrm{O}_{\mathrm{w} 1}\right)$. 
Table 1. Summary of crystallographic data for the structures

\begin{tabular}{|c|c|c|}
\hline Compounds & $\mathrm{Ce}_{1.14} \mathrm{Na}_{0.57} \mathrm{C}_{16} \mathrm{O}_{13} \mathrm{H}_{18}$ & $\mathrm{La}_{1.14} \mathrm{Na}_{0.57} \mathrm{C}_{16} \mathrm{O}_{13} \mathrm{H}_{18}$ \\
\hline Notation & CeMOF & LaMOF \\
\hline Molecular weight $\left(\mathrm{g} \mathrm{mol}^{-1}\right)$ & 591.1 & 588.7 \\
\hline Crystal system & \multirow{2}{*}{\multicolumn{2}{|c|}{$\begin{array}{l}\text { Tetragonal } \\
P 4_{2} 2{ }_{1} 2\end{array}$}} \\
\hline Space group & & \\
\hline $\mathrm{a}(\AA)$ & 21.9543(13) & 22.0138(14) \\
\hline c $(\AA)$ & $4.1070(3)$ & $4.1253(4)$ \\
\hline $\mathrm{V}\left(\AA^{3}\right)$ & 1979.5(3) & 1999.2(3) \\
\hline $\mathrm{Z}, \rho_{\text {calc. }}\left(\mathrm{g} \mathrm{cm}^{-3}\right)$ & 4, 1.984 & 4, 1.954 \\
\hline Wavelength $(\AA)$ & $\mathrm{MoK}_{\alpha}$ & $\mathrm{MoK}_{\alpha}$ \\
\hline$\mu / \mathrm{mm}-1$ & 2.694 & 2.508 \\
\hline \multirow[t]{2}{*}{$2 \theta$ range $\left(^{\circ}\right)$} & $4.0-56.4$ & $4.1-60.0$ \\
\hline & $-27 \leq \mathrm{h} \leq 28$ & $-29 \leq h \leq 23$ \\
\hline \multirow[t]{2}{*}{ Limiting indices } & $-28 \leq \mathrm{k} \leq 19$ & $-29 \leq \mathrm{k} \leq 18$ \\
\hline & $-5 \leq 1 \leq 5$ & $-5 \leq 1 \leq 5$ \\
\hline Collected reflections & 17190 & 11290 \\
\hline Refl. uni. & 2274 & 2898 \\
\hline Refined parameters & 156 & 154 \\
\hline Goodness-of-fit on $\mathrm{F}^{2}$ & 1.014 & 1.104 \\
\hline \multirow{2}{*}{ Final $R$ indices $[\mathrm{I}>2 \sigma(\mathrm{I})]$} & $\mathrm{R}_{1}=0.0431$ & $\mathrm{R}_{1}=0.0505$ \\
\hline & $\mathrm{Rw}_{1}=0.0845$ & $\mathrm{Rw}_{1}=0.0952$ \\
\hline \multirow{2}{*}{$\mathrm{R}$ indices (all data) } & $\mathrm{R}_{1}=0.0698$ & $\mathrm{R}_{1}=0.0921$ \\
\hline & $\mathrm{Rw}_{1}=0.0953$ & $\mathrm{Rw}_{1}=0.1095$ \\
\hline $\begin{array}{l}\text { Largest diff. peak and } \\
\text { hole/e. } \AA^{-3}\end{array}$ & $0.602 /-0.753$ & $0.755 /-0.854$ \\
\hline
\end{tabular}

\section{Thermal behavior of the LnMOF}

The thermal behavior of both LaMOF and CeMOF was investigated by a multiple set of techniques. Fist, both TG curves exhibits a flat plateau above $150^{\circ} \mathrm{C}$, whose position matches with the full dehydration of the solids (CeMOF: experimental and theoretical weight losses are 15.6\% and 15.2\% respectively; LaMOF: experimental and theoretical weight losses are $15.7 \%$ and $15.3 \%$ respectively) (Figure S8). X-ray powder thermodiffraction experiments were performed under ambient air from 30 to $200^{\circ} \mathrm{C}$ to investigate the dehydrated form. It showed that the water departure is associated with a major structural change at ca. $90^{\circ} \mathrm{C}$ and a significant decrease of crystallinity. 
Pattern matching refinements (Le Bail method) were carried out for each temperature to follow the lattice parameters evolution. Surprisingly, all diffraction data could have been easily fitted by using the same lattice parameters of LaMOF and CeMOF, indicating that the crystal system and space group are maintained even for the dehydrated form. During the thermal treatment, the lattice volume decreases of $18.8 \%$ (Figure $2 \mathrm{~b}$ ) while the $a$ and $c$ parameters decrease of 7.3 and $5.6 \%$, respectively (Figure S9). In the same way, the CeMOF compound exhibits a 21.2\% decrease in volume (Figure S10) associated to a $7.1 \%$ and $8.7 \%$ decrease in $a$ and $c$ parameters (Figure S11), respectively. Unfortunately, the moderate crystallinity of the dehydrated forms precluded any structure refinement by Rietveld techniques. Nevertheless, nitrogen sorption experiments carried out a $77 \mathrm{~K}$ on the dehydrated solids resulted in a very low BET surface values $\left(\approx 9 \mathrm{~m}^{2} / \mathrm{g}\right)$, indicative of non-porous solids. This suggests that the dehydration is accompanied with a shrinkage of the pores resulting from the reorganization of the coordination sphere around the cation, as commonly found in Ln-MOFs ${ }^{[36]}$. Considering the crystal structure, one can hypothesize that, upon departure of bound water molecule, the pendant carboxylate oxygen atom starts to interact with the Ln ions. This is in line with the FTIR analysis, which shows the disappearance of the shoulder at $1670 \mathrm{~cm}^{-}$ ${ }^{1}$ characteristic of the dangling $\mathrm{C}=\mathrm{O}$ bond upon dehydration (Figure S12). It is also expected that, upon the loss of their hydration sphere, the cation embedded in the cavities, specially $\mathrm{Ln}^{3+}$, will also strongly interact with the oxygen atom of the ligands, precluding the reopening of the channels. This dehydration process is indeed irreversible under air and the native LnMOF is not recovered in these conditions (Figure $2 \mathrm{~b}$ ). Finally, the irreversibility of the desolvation process was also probed immersing the dehydrated compound of LaMOF in various solvents for 2 hours, namely water, $\mathrm{MeOH}, \mathrm{CH}_{3} \mathrm{CN}$ and $\mathrm{DMF}$, and further analyzing its structure by PXRD in a capillary tube (Figure S13). For the three organic solvents, the structure is not modified, the volume 
lattice (determined by Le Bail refinement) remains similar to the dehydrated form. Surprisingly, the immersion in water leads to a decomposition of the MOF and the formation of the initial coordination polymer La-CP as indicated by XRD and FTIR analyses (Figures S13 and S14).

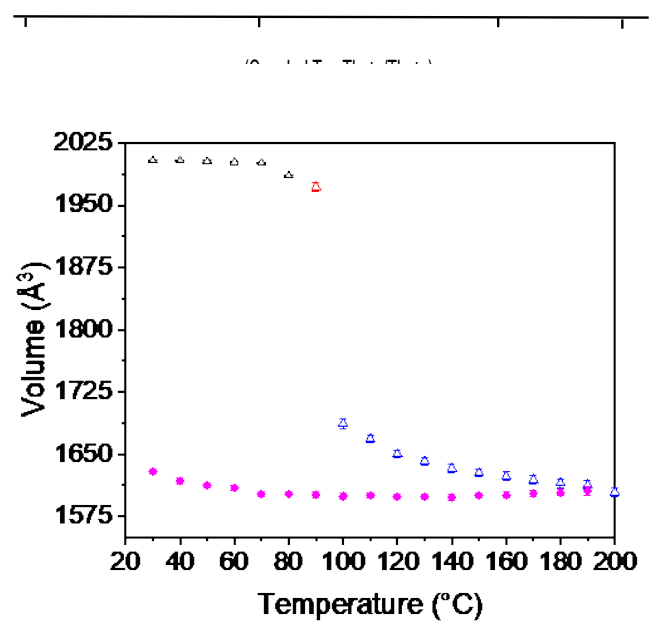

Figure 2. a) X-ray thermodiffractogram of LaMOF performed under air from $30^{\circ} \mathrm{C}$ to $200^{\circ} \mathrm{C}$ using a $10^{\circ} \mathrm{C}$ step. Black: as-synthesized form, blue: dehydrated form, red: mixture of the assynthesized form and the dehydrated one. b) Lattice volume evolution with the temperature from 30 to $200^{\circ} \mathrm{C}$ (black, red and blue points) and from 200 to $30^{\circ} \mathrm{C}$ (magenta points). The volume was determined from Le Bail refinements of the corresponding XRD patterns. 


\section{Luminescence properties}

The LaMOF compound was easily doped by small contents of the optically active ions $\mathrm{Eu}^{3+}$ and $\mathrm{Tb}^{3+}$. All doped materials, namely LaMOF-1\%Eu, LaMOF-1\%Tb, and LaMOF-Eu-Tb were isostructural to the LaMOF as confirmed by XRD, FTIR and thermal analyses (Figures S15S17).

Solid-state luminescence behaviour of LaMOF was investigated as a potential blue emitter for the generation of white emission compound. Under UV irradiation ( $\left.\lambda_{\text {exc }}=340 \mathrm{~nm}\right)$, LaMOF exhibits a broad emission band centred at $400 \mathrm{~nm}$ (Figure S18) corresponding to the $\pi-\pi^{*}$ transition of the ligand. Thus, LaMOF gets a blue emission with CIE chromatic coordinates equal to (0.1836, 0.1259) (Figure S19). Compared to the emission of the pure ligand (Figure S5 in reference 23) ${ }^{[28]}$, a small red-shift is observed for the coordinated ligand, which may result from a slight change in intra- and inter-molecular interactions between ligands ${ }^{[15]}$.

Doping LaMOF with $1 \%$ of $\mathrm{Tb}^{3+}$ or $\mathrm{Eu}^{3+}$ leads to the formation of crystals with a perfectly homogeneous luminescence (Figure S20). The emission spectra of doped compounds, LaMOF1\%Eu and LaMOF-1\%Tb, are composed of the ligand-based blue emission and of the characteristic sharp lines of $\mathrm{Eu}^{3+}$ and $\mathrm{Tb}^{3+}$ ions corresponding to the ${ }^{5} \mathrm{D}_{0} \rightarrow{ }^{7} \mathrm{~F}_{\mathrm{J}}(\mathrm{J}=0-4) \mathrm{Eu}^{3+}$ transitions and to the ${ }^{5} \mathrm{D}_{4} \rightarrow{ }^{7} \mathrm{~F}_{\mathrm{J}}(\mathrm{J}=3-6) \mathrm{Tb}^{3+}$ transitions. Excitation spectra were monitored at different emission wavelengths, within the emission band of the ligand ( $\lambda_{\mathrm{em}}=400 \mathrm{~nm}$ ) within the ${ }^{5} \mathrm{D}_{0} \rightarrow{ }^{7} \mathrm{~F}_{2} \mathrm{Eu}^{3+}$ transition (615 nm) and within the ${ }^{5} \mathrm{D}_{4} \rightarrow{ }^{7} \mathrm{~F}_{5} \mathrm{~Tb}^{3+}$ transition (545 nm) (Figures 3a and 4a). It then becomes clear that it is possible to modulate the emission of the ligand in relation to the emission of the lanthanide with the excitation wavelength. The excitation wavelength impacts the transferred energy form the ligand to the $\mathrm{Ln}^{3+}$ cations to allow the coexistence of the 
ligand and $\mathrm{Ln}^{3+}$ ions emissions but also to modulate the emission intensities of the three colours ${ }^{[20]}$. Thus four different excitation wavelengths have been chosen: 258 and $289 \mathrm{~nm}$ where the $\mathrm{Ln}^{3+}$ emission is more intense than the blue ligand emission, $321 \mathrm{~nm}$ where the ligand emission is significantly predominant and $312 \mathrm{~nm}$ where both emissions are more balanced. Emission spectra have been recorded for each excitation wavelength (Figures 3b and 4b) and CIE parameters were calculated each time. Thus, the CIE coordinates of LaMOF-1\%Eu vary linearly from red to violet with an increase of the excitation wavelength while the CIE data of LaMOF-1\%Tb move from green to cyan (Figures $3 \mathrm{~b}$ and $4 \mathrm{~b}$ ). Emission lifetimes were determined for the ${ }^{5} \mathrm{D}_{0} \rightarrow{ }^{7} \mathrm{~F}_{2} \mathrm{Eu}^{3+}$ transition in LaMOF-1\%Eu, and for the ${ }^{5} \mathrm{D}_{4} \rightarrow{ }^{7} \mathrm{~F}_{5} \mathrm{~Tb}^{3+}$ transition in LaMOF-1\% Tb (Table 1), where a monoexponential behaviour was observed for all compounds. The average lifetime for the $\mathrm{Eu}^{3+}$ main emission is $600 \mu$ s while it is equal to $1.23 \mathrm{~ms}$ for the $\mathrm{Tb}^{3+}$ main emission. Finally, the three doped samples exhibit a quite moderate quantum yield with an average value of $10 \%$. 

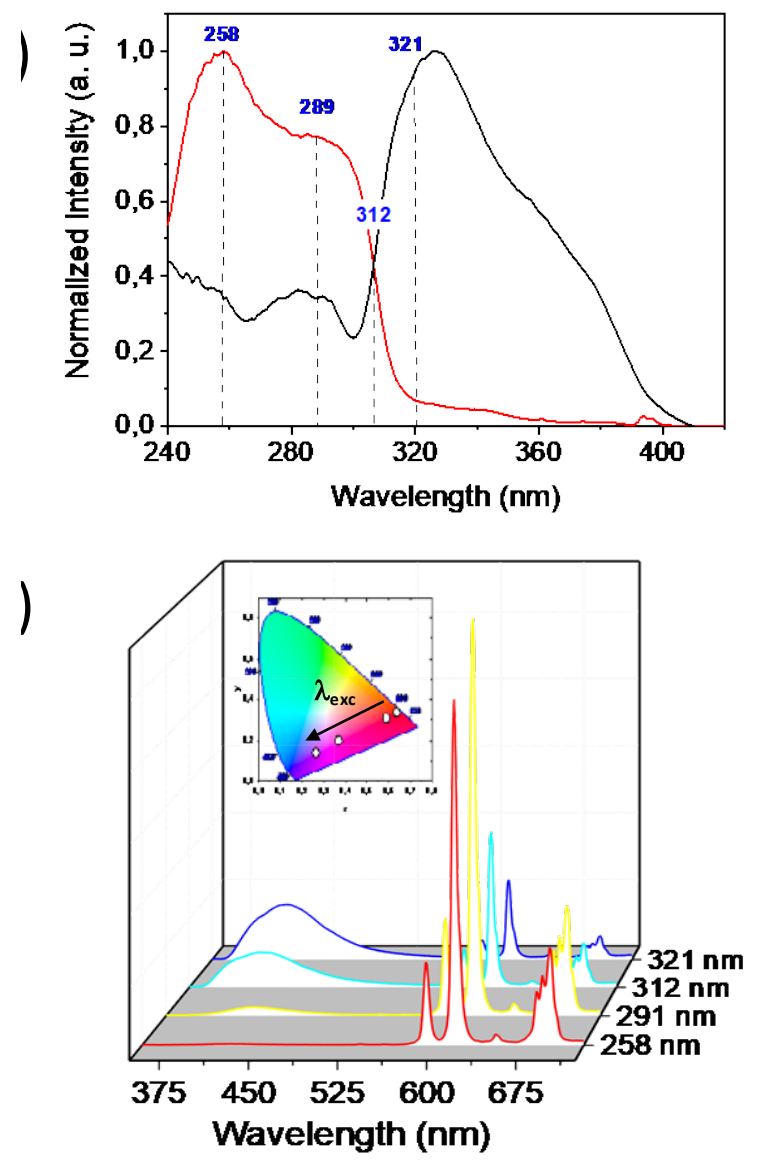

Figure 3. a) PLE spectra of LaMOF-1\%Eu monitored at $\lambda_{\mathrm{em}}=425 \mathrm{~nm}$ (black line), within the ligand emission band, and monitored at $\lambda_{\mathrm{em}}=615 \mathrm{~nm}$ (red line), within the ${ }^{5} \mathrm{D}_{0} \rightarrow{ }^{7} \mathrm{~F}_{2} \mathrm{Eu}^{3+}$ transition. b) PL spectra of LaMOF-1\%Eu monitored at different excitation wavelengths and corresponding CIE parameters reported on a chromaticity diagram. 

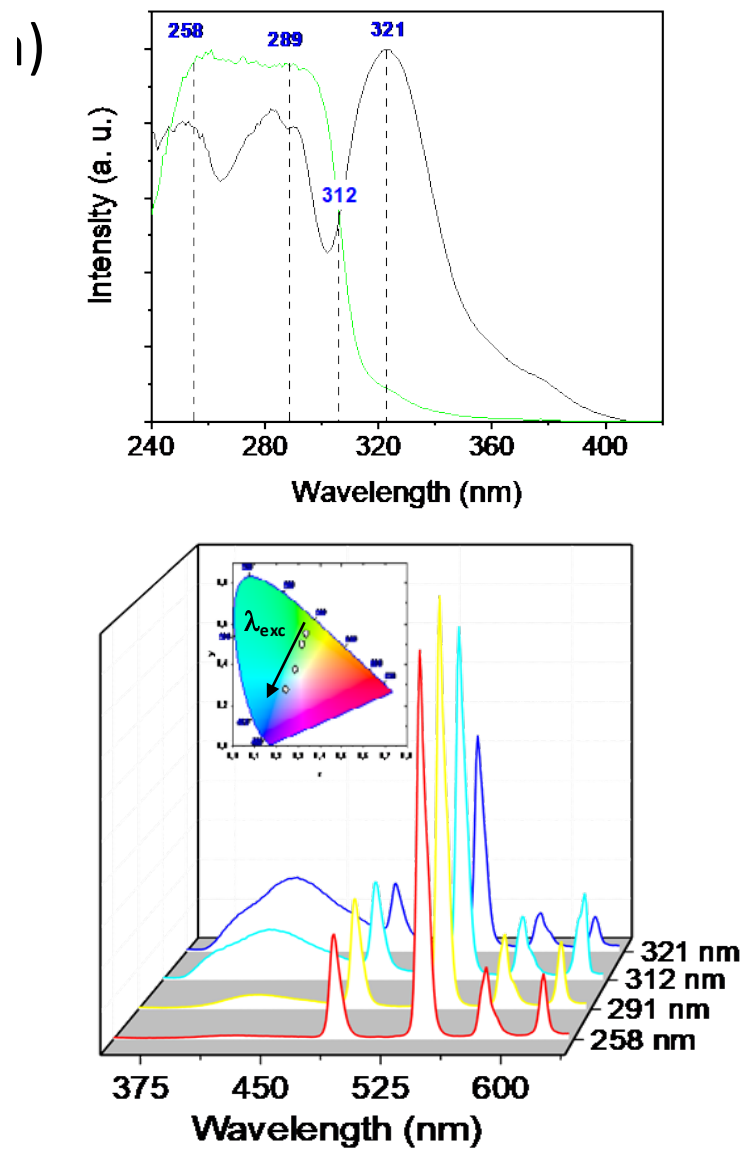

Figure 4. a) PLE spectra of LaMOF-1\% Tb monitored at $\lambda_{\mathrm{em}}=425 \mathrm{~nm}$ (black line), within the ligand emission band, and monitored at $\lambda_{\text {em }}=543 \mathrm{~nm}$ (green line), within the ${ }^{5} \mathrm{D}_{4} \rightarrow{ }^{7} \mathrm{~F}_{5} \mathrm{~Tb}^{3+}$ transition. b) PL spectra of LaMOF-1\% Tb monitored at different excitation wavelengths and corresponding CIE parameters reported on a chromaticity diagram.

The white-light emitting materials can be designed as a single phase by an adjustment of each colour emission intensities, which is possible by a fine control of $\mathrm{Eu}^{3+}$ and $\mathrm{Tb}^{3+}$ content but also by varying the excitation wavelength. The amount of $\mathrm{Eu}^{3+}$ was deliberately chosen far less than that of $\mathrm{Tb}^{3+}$ because the latter has a high efficiency due to the lowest emitting level $\mathrm{Eu}^{3+}(17500$ $\left.\mathrm{cm}^{-1}\right)$ compared to the $\mathrm{Tb}^{3+}\left(20500 \mathrm{~cm}^{-1}\right)$. Thus, after a careful screening, the compound LaMOFEu-Tb was obtained, with a molar content of $\mathrm{Tb}^{3+}$ and $\mathrm{Eu}^{3+}$ equal to 1\%, and $0.25 \%$, respectively. 
Emission spectra have been monitored at the four different excitation wavelength and CIE parameters were calculated and reported on the chromaticity diagram (Figure 5). As expected, the corresponding luminescence emission of LaMOF-Eu-Tb falls in the white light region with CIE coordinates on the range of $(0.3440,0.3735)$ to $(0.2679,0.3014)$ when the excitation wavelength varies between 312 and $321 \mathrm{~nm}$.

Emission lifetimes were also determined for the ${ }^{5} \mathrm{D}_{0} \rightarrow{ }^{7} \mathrm{~F}_{2} \mathrm{Eu}^{3+}$ transition and the ${ }^{5} \mathrm{D}_{4} \rightarrow{ }^{7} \mathrm{~F}_{5} \mathrm{~Tb}^{3+}$ transition in LaMOF-Eu-Tb (Table 2). Then, the $\mathrm{Tb}^{3+}$-to-Eu ${ }^{3+}$ energy transfer rate and the transfer efficiency were determined from Equation (1) ${ }^{[37-39]}$ :

$$
\eta_{E T}=1-\frac{\tau}{\tau_{0}}
$$

where $\tau$ and $\tau_{0}$ corresponding to the lifetimes of the donor in the presence and absence of the acceptor, respectively. Although the contents of $\mathrm{Eu}^{3+}$ and $\mathrm{Tb}^{3+}$ are low, there is little $\mathrm{Tb}^{3+}$-to- $\mathrm{Eu}^{3+}$ energy transfer which ranging from $1.51 \%$ to $10.71 \%$ when the excitation wavelength increases (Table 2). Consequently, the excitation wavelength influences the antenna effect of the ligand but also the $\mathrm{Tb}^{3+}$-to-Eu ${ }^{3+}$ energy transfer which is a crucial parameter to equilibrate the green-red balance. ${ }^{[40-42]}$ 

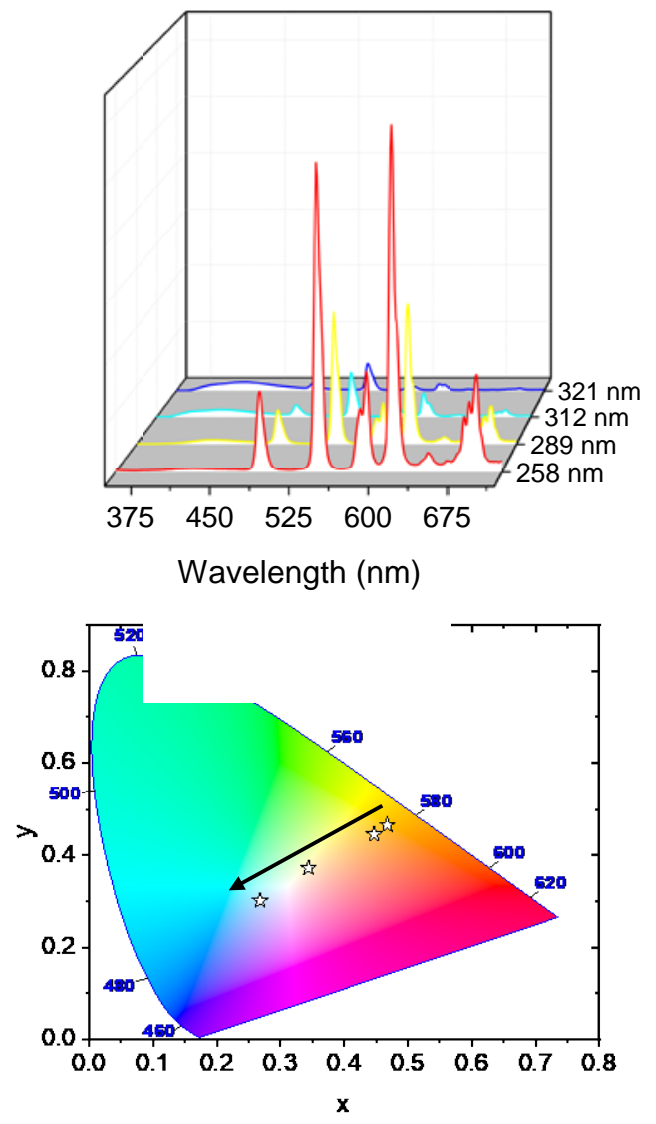

Figure 5. a) PL spectra of LaMOF-Eu-Tb monitored at different excitation wavelengths and b) corresponding CIE parameters reported on a chromaticity diagram.

Table 2. Decay times values for LaMOF-1\%Eu, LaMOF-1\%Tb and LaMOF-Eu-Tb compounds, and $\mathrm{Tb}^{3+}$-to-Eu ${ }^{3+}$ energy transfer efficiency in the bimetallic material.

\begin{tabular}{c|c|c|ccc}
\hline & LaMOF-1\%Eu & LaMOF-1\%Tb & \multicolumn{3}{|c}{ LaMOF-EuTb } \\
$\begin{array}{c}\text { Excitation } \\
\text { wavelength }\end{array}$ & ${ }^{5} \mathrm{D}_{0} \rightarrow{ }^{7} \mathrm{~F}_{2} \mathrm{Eu}^{3+}$ & ${ }^{5} \mathrm{D}_{0} \rightarrow{ }^{7} \mathrm{~F}_{2} \mathrm{~Tb}^{3+}$ & ${ }^{5} \mathrm{D}_{0} \rightarrow{ }^{7} \mathrm{~F}_{2} \mathrm{Eu}^{3+}$ & ${ }^{5} \mathrm{D}_{0} \rightarrow{ }^{7} \mathrm{~F}_{2} \mathrm{~Tb}^{3+}$ & $\mathrm{ET} \mathrm{efficiency}(\%)^{3}$ \\
\hline $258 \mathrm{~nm}$ & $594 \pm 2 \mu \mathrm{s}$ & $1.26 \pm 0.01 \mathrm{~ms}$ & $594 \pm 4 \mu \mathrm{s}$ & $1.241 \pm 0.006 \mathrm{~ms}$ & 1.51 \\
$289 \mathrm{~nm}$ & $569 \pm 4 \mu \mathrm{s}$ & $1.269 \pm 0.007 \mathrm{~ms}$ & $598 \pm 4 \mu \mathrm{s}$ & $1.216 \pm 0.009 \mathrm{~ms}$ & 3.49 \\
$312 \mathrm{~nm}$ & $580 \pm 5 \mu \mathrm{s}$ & $1.207 \pm 0.008 \mathrm{~ms}$ & $630 \pm 12 \mu \mathrm{s}$ & $1.17 \pm 0.01 \mathrm{~ms}$ & 7.14 \\
$321 \mathrm{~nm}$ & $649 \pm 4 \mu \mathrm{s}$ & $1.176 \pm 0.004 \mathrm{~ms}$ & $715 \pm 7 \mu \mathrm{s}$ & $1.125 \pm 0.02 \mathrm{~ms}$ & 10.71 \\
\hline
\end{tabular}




\section{CONCLUSION}

Two new lanthanide MOF built upon isophthalate, $\mathrm{Ln}_{1.14} \mathrm{Na}_{0.57}(\mathrm{BDC})_{2}\left(\mathrm{H}_{2} \mathrm{O}\right) \cdot 4 \mathrm{H}_{2} \mathrm{O}\left(\mathrm{Ln}=\mathrm{La}^{3+}\right.$ or $\mathrm{Ce}^{3+}$ ), were synthesized by the hydrothermal conversion of a coordination compound. The threedimensional network consists in chains of face-sharing $\left[\mathrm{LnO}_{10}\right]$ polyhedra connected by the linker molecules to form alternating polar and apolar channels. The latter are occupied by water molecules and disordered $\mathrm{Ln}^{3+}$ and $\mathrm{Na}^{+}$cations provided from the basic solution used during the synthesis. The dehydration process was investigated by thermodiffraction. When the water molecules are removed, one observes a shrink of the lattice volume leading to a non porous character. This process was found to be irreversible both in air and in suspension of various solvents, in line with the strong structural reorganization occurring around the $\mathrm{Ln}^{3+}$ cations. Finally, the LaMOF counterpart has been easily doped by $\mathrm{Eu}^{3+}$ and $\mathrm{Tb}^{3+}$ in appropriate ratios to provide a white emission material. The tuning of the excitation wavelength enables the modulation of the antenna effect from the ligand to the $\mathrm{Ln}^{3+}$ emitting levels but also the variation of the $\mathrm{Tb}^{3+}$ to-Eu ${ }^{3+}$ energy transfer efficiency. Consequently, a fine adjustment of the excitation wavelength allowed to get emission in the white domain (CIE coordinates $(0.3440,0.3735)$ at $\left.\lambda_{\text {exc }}=312 \mathrm{~nm}\right)$.

\section{EXPERIMENTAL SECTION}

Chemicals and Materials. $\mathrm{CeCl}_{3} \cdot 7 \mathrm{H}_{2} \mathrm{O}$ (Aldrich, 99.9\%), $\mathrm{La}\left(\mathrm{NO}_{3}\right)_{3} \cdot 6 \mathrm{H}_{2} \mathrm{O}$ (Alfa Aesar, 99.9\%), $\mathrm{TbCl}_{3} \cdot 6 \mathrm{H}_{2} \mathrm{O}$ (Alfa Aesar, 99.99\%), Eu(NO3) $)_{3} \cdot 6 \mathrm{H}_{2} \mathrm{O}$ (Alfa Aesar, 99.99\%) and 1,3- $\mathrm{H}_{2} \mathrm{BDC}$ (Alfa Aesar, 98\%) were used without further purification. 
Synthesis of CeMOF. 1,3- $\mathrm{H}_{2} \mathrm{BDC}$ (574 mg, $3.46 \mathrm{mmol}$ ) was dissolved in $11 \mathrm{~mL}$ of an aqueous $\mathrm{NaOH}$ solution $(0.70 \mathrm{M})$ while $\mathrm{CeCl}_{3} \cdot 7 \mathrm{H}_{2} \mathrm{O}(645 \mathrm{mg}, 1.73 \mathrm{mmol})$ was dissolved in $2 \mathrm{~mL}$ dezionized water. The two solutions were mixed under stirring and a white precipitate was formed (Ce-CP). The pH of the mixture was adjusted at 5 by addition of small amount of an $\mathrm{HCl}$ solution (1 M) to obtain the formation of a white precipitate. Then, the above mixture was placed in a sealed $21 \mathrm{ml}$ Teflon-lined stainless vessel, which was heated at $150^{\circ} \mathrm{C}$ for 3 days under autogenous pressure and cooled down to room temperature. Colorless needle-like crystals were obtained. Yield: 80.3\%. Anal. Calcd for $\mathrm{Ce}_{1.14} \mathrm{Na}_{0.57} \mathrm{C}_{16} \mathrm{O}_{13} \mathrm{H}_{18}$ (\%): C, 32.51; H, 3.05. Found: C, 32.03; H, 2.93. IR (KBr pellet, cm ${ }^{-1}$ ): 1676 (sh),1616 (vs), 1599 (vs), 1541 (vs), 1511 (s), 1475 (s), 1452 (vs), 1389 (vs), 1313 (m), 1275 (m), 1155 (m), 1072 (m), 926 (m), 820 (m), 743 (s), 710 (s), 658 (m), $569(\mathrm{~m}), 521(\mathrm{~m})$ and $422(\mathrm{~m})$.

Synthesis of LaMOF. 1,3- $\mathrm{H}_{2} \mathrm{BDC}(574 \mathrm{mg}, 3.46 \mathrm{mmol}$ ) was dissolved in $11 \mathrm{~mL}$ of an aqueous $\mathrm{NaOH}$ solution $(0.70 \mathrm{M})$ while $\mathrm{La}\left(\mathrm{NO}_{3}\right)_{3} \cdot 6 \mathrm{H}_{2} \mathrm{O}(750 \mathrm{mg}, 1.73 \mathrm{mmol})$ was dissolved in $2 \mathrm{~mL}$ dezionized water. The two solutions were mixed under stirring and a white precipitate was formed (La-CP). The $\mathrm{pH}$ of the mixture was adjusted at 5 by addition of small amount of an $\mathrm{HCl}$ solution $(1 \mathrm{M})$ to obtain the formation of a white precipitate. Then, the above mixture was placed in a sealed $21 \mathrm{ml}$ Teflon-lined stainless vessel, which was heated at $180^{\circ} \mathrm{C}$ for 5 days under autogenous pressure and cooled down to room temperature. Colorless needle-like crystals were obtained. Yield: 85.9\%. Anal. Calcd for $\mathrm{La}_{1.14} \mathrm{Na}_{0.57} \mathrm{C}_{16} \mathrm{O}_{13} \mathrm{H}_{18}$ (\%): C, 32.80; H, 3.07. Found: C, 32.70; H, 3.02. IR (KBr pellet, $\mathrm{cm}^{-1}$ ): 1668 (sh),1612 (vs), 1599 (vs), 1541 (vs), 1510 (s), 1475 (s), 1452 (vs), 1389 (vs), 1315 (m), 1275 (m), 1155 (m), 1072 (m), 924 (m), 820 (m), 743 (s), 710 (s), 658 (m), $569(\mathrm{~m}), 519(\mathrm{~m})$ and $422(\mathrm{~m})$. 
Synthesis of LaMOF-1\%Eu. The procedure was the same as that for LaMOF except that the cationic solution was composed by $\mathrm{La}\left(\mathrm{NO}_{3}\right)_{3} \cdot 6 \mathrm{H}_{2} \mathrm{O}(742 \mathrm{mg}, 1.71 \mathrm{mmol})$ and $\mathrm{Eu}\left(\mathrm{NO}_{3}\right)_{3} \cdot 6 \mathrm{H}_{2} \mathrm{O}$ (7.4 mg, $0.02 \mathrm{mmol}$ ). Yield: 82.3\%. The Eu/La ratio was determined by ICP-AES to be equal to $1.08 \%$.

Synthesis of LaMOF-1\%Tb. The procedure was the same as that for LaMOF except that the cationic solution was composed by $\mathrm{La}\left(\mathrm{NO}_{3}\right)_{3} \cdot 6 \mathrm{H}_{2} \mathrm{O}(742 \mathrm{mg}, 1.71 \mathrm{mmol})$ and $\mathrm{TbCl}_{3} \cdot 6 \mathrm{H}_{2} \mathrm{O}(6.5$ mg, $0.02 \mathrm{mmol}$ ). Yield: $78.8 \%$. The Tb/La ratio was determined by ICP-AES to be equal to $1.02 \%$.

Synthesis of LaMOF-Eu-Tb. The procedure was the same as that for LaMOF except that the cationic solution was composed by $\mathrm{La}\left(\mathrm{NO}_{3}\right)_{3} \cdot 6 \mathrm{H}_{2} \mathrm{O}(741 \mathrm{mg}, 1.71 \mathrm{mmol}), \mathrm{Eu}\left(\mathrm{NO}_{3}\right)_{3} \cdot 6 \mathrm{H}_{2} \mathrm{O}(1.9$ mg, $0.004 \mathrm{mmol}$ ), and $\mathrm{TbCl}_{3} \cdot 6 \mathrm{H}_{2} \mathrm{O}$ (6.5 mg, $\left.0.02 \mathrm{mmol}\right)$. Yield: 81.9\%. The Eu/La and $\mathrm{Tb} / \mathrm{La}$ ratio were determined by ICP-AES to be equal to $0.21 \%$ and $1.03 \%$, respectively.

\section{Characterization}

Powder X-ray Diffraction spectra were monitored using a D8 Bruker diffractometer in the Bragg-Brentano geometry, equipped with a front germanium monochromator, a copper anode (CuK-L3 radiation $\lambda=1.540598 \AA$ ) and a LynxEye PSD detector. Le Bail refinements were performed with the full-matrix least-squares technique using the Jana2006 program ${ }^{[43]}$. The errors

bars on all parameters were calculated as three times the Berar's ${ }^{[44]}$ coefficient multiplied by the standard deviation. FTIR spectra were recorded in the $4000-400 \mathrm{~cm}^{-1}$ range on a Bruker Vertex equipped with a computer control using the OPUS software. Thermogravimetric analysis (TGA) was performed by flowing dry air with a heating and cooling rate of $5^{\circ} \mathrm{C} / \mathrm{min}$ on a SETARAM TG-DSC 111 between 20 and $800^{\circ} \mathrm{C}$. Room-temperature photoluminescence spectra were recorded on a Jobin-Yvon Fluorolog 3 fluorimeter equipped with a CCD camera (excitation 
source: $450 \mathrm{~W}$ Xe arc lamp). The emission spectra were corrected for detection and optical spectral response of the spectrofluorimeter and the excitation spectra were weighed for the spectral distribution of the lamp intensity using a photodiode reference detector. Quantum yields have been performed with a integration sphere connected to our device.

Single crystals were selected and isolated using an optical microscope; they were mounted on MicroMount needles (MiTeGen). X-ray single crystal data were collected on an APEX II Quazar diffractometer (4-circle Kappa goniometer, $\mathrm{I} \mu \mathrm{S}$ microfocus source (Mo K $\alpha$ ), CCD detector). The structures were determined by direct methods with SHELXS-97 and SHELXL-97 programs included in WINGX package ${ }^{[45,46]}$. All non-hydrogen atoms positions were refined anisotropically. Hydrogen atoms of the carboxylate molecules were geometrically constrained (HFIX options) whereas hydrogen atoms of the coordinated water molecules were constrained with DFIX options. The hydrogen atoms of free water molecules were not placed. The assignment of the atoms in metal/alkaline environments was based on M-O distances and thermal motion considerations (Table S1-S6). ${ }^{[47-49]}$ The conditions of data collection are summarized in Table $1 .{ }^{[50]}$ Crystallographic data (excluding structure factors) for structures have been deposited with the Cambridge Crystallographic Data Centre as supplementary publication nos. 2013537 $\left(\mathrm{Ce}_{1.14} \mathrm{Na}_{0.57} \mathrm{C}_{16} \mathrm{O}_{9} \mathrm{H}_{18}\right)$ and $2013538\left(\mathrm{La}_{1.14} \mathrm{Na}_{0.57} \mathrm{C}_{16} \mathrm{O}_{9} \mathrm{H}_{18}\right)$. Copies of the data can be obtained, free of charge, on application to CCDC, 12 Union Road, Cambridge CB2 1EZ, UK, (fax: +44 1223 336033 or e-mail: deposit@ccdc.cam.ac.uk).

Keywords : metal-organic frameworks, lanthanide, thermal behaviour, white luminescence 


\section{ACKNOWLEDGMENT}

The authors attached to the IMMM institute gratefully acknowledge the "X-ray Diffusion and Diffraction" technical platform of IMMM (Le Mans University). V.T. thanks la Fondation de la Maison de la Chimie for his postdoctoral fellowship. 


\section{REFERENCES}

[1] W. P. Lustig, S. Mukherjee, N. D. Rudd, A. V. Desai, J. Li, S. K. Ghosh, Chem. Soc. Rev. 2017, 46, 3242-3285.

[2] F. Artizzu, F. Quochi, A. Serpe, Inorg. Chem. Front. 2015, 2, 213-222.

[3] J. Rocha, C. D. S. Brites, L. D. Carlos, Chem. - A Eur. J. 2016, 22, 14782-14795.

[4] Z. Hu, B. J. Deibert, J. Li, Chem Soc Rev 2014, 43, 5815-5840.

[5] N. Busschaert, C. Caltagirone, W. Van Rossom, P. A. Gale, Chem. Rev. 2015, 115, 80388155.

[6] Y. Cui, F. Zhu, B. Chen, G. Qian, Chem. Commun. 2015, 51, 7420-7431.

[7] D. Tian, Y. Li, R. Y. Chen, Z. Chang, G. Y. Wang, X. H. Bu, J. Mater. Chem. A 2014, 2, 1465-1470.

[8] X. L. Zhao, D. Tian, Q. Gao, H. W. Sun, J. Xu, X. H. Bu, Dalt. Trans. 2016, 45, 10401046.

[9] L. Xu, Y. Li, Q.-J. Pan, D. Wang, S. Li, G. Wang, Y. Chen, P. Zhu, W. Qin, ACS Appl. Mater. Interfaces 2020, 12, 18934-18943.

[10] W. P. Lustig, Z. Shen, S. J. Teat, N. Javed, E. Velasco, D. M. O’Carroll, J. Li, Chem. Sci. 2020, 11, 1814-1824.

[11] F. Igoa, G. Peinado, L. Suescun, C. Kremer, J. Torres, J. Solid State Chem. 2019, 279, 
120925.

[12] N. Zhang, Q. Guan, C. Liu, Y. Sun, B. Li, Y. Xing, F. Bai, Appl. Organomet. Chem. 2020, 34, DOI 10.1002/aoc.5506.

[13] H. S. Jena, A. M. Kaczmarek, C. Krishnaraj, X. Feng, K. Vijayvergia, H. Yildirim, S. N. Zhao, R. Van Deun, P. Van Der Voort, Cryst. Growth Des. 2019, 19, 6339-6350.

[14] J. Wu, H. Zhang, S. Du, J. Mater. Chem. C 2016, 4, 3364-3374.

[15] Y. W. Zhao, F. Q. Zhang, X. M. Zhang, ACS Appl. Mater. Interfaces 2016, 8, 24123-24130.

[16] Y. Gai, Q. Guo, K. Xiong, F. Jiang, C. Li, X. Li, Y. Chen, C. Zhu, Q. Huang, R. Yao, M. Hong, Cryst. Growth Des. 2017, 17, 940-944.

[17] Y. Y. An, L. P. Lu, S. S. Feng, M. L. Zhu, CrystEngComm 2018, 20, $2043-2052$.

[18] L. Qiu, C. Yu, X. Wang, Y. Xie, A. M. Kirillov, W. Huang, J. Li, P. Gao, T. Wu, X. Gu, Q. Nie, D. Wu, Inorg. Chem. 2019, 58, 4524-4533.

[19] Q. Li, J. Qian, J. Zhou, L. Du, Q. Zhao, CrystEngComm 2020, 22, 2667-2674.

[20] J. J. Huang, J. H. Yu, F. Q. Bai, J. Q. Xu, Cryst. Growth Des. 2018, 18, 5353-5364.

[21] M. Yu, X. Yao, X. Wang, Y. Li, G. Li, Polymers (Basel). 2019, 11, 99.

[22] H. Yan, H. Ni, J. Jia, C. Shan, T. Zhang, Y. Gong, X. Li, J. Cao, W. Wu, W. Liu, Y. Tang, Anal. Chem. 2019, 91, 5225-5234.

[23] N. Zhang, Q. Guan, C. Liu, Y. Sun, B. Li, Y. Xing, F. Bai, Appl. Organomet. Chem. 2020, 
34, DOI 10.1002/aoc.5506.

[24] M. L. Ma, C. Ji, S. Q. Zang, Dalt. Trans. 2013, 42, 10579-10586.

[25] Y. Yang, L. Chen, F. Jiang, M. Yu, X. Wan, B. Zhang, M. Hong, J. Mater. Chem. C 2017, DOI 10.1039/C6TC05316E.

[26] D. F. He, F. jiang Zhou, J. J. Deng, F. Luo, H. Xue, F. kun Meng, L. qun Sun, H. sheng Liu, S. X. Liu, Inorg. Chem. Commun. 2018, 96, 43-46.

[27] P. Mahata, K. V Ramya, S. Natarajan, Dalt. Trans. 2007, 4017-4026.

[28] I. N’Dala-Louika, D. Ananias, C. Latouche, R. Dessapt, L. D. Carlos, H. Serier-Brault, J. Mater. Chem. C 2017, 5, 10933-10937.

[29] F. Zarekarizi, A. Morsali, Inorg. Chem. 2020, 59, 2988-2996.

[30] Y. Ge, B. Teng, L. Lv, R. Chen, B. Wu, Cryst. Growth Des. 2020, 20, 486-497.

[31] Y. Pan, W. Liu, D. Liu, Q. Ding, J. Liu, H. Xu, M. Trivedi, A. Kumar, Inorg. Chem. Commun. 2019, 100, 92-96.

[32] S. Kuno, H. Akeno, H. Ohtani, H. Yuasa, Phys. Chem. Chem. Phys. 2015, 17, 15989-15995.

[33] Y. Zheng, K. Liu, H. Qiao, Y. Zhang, Y. Song, M. Yang, Y. Huang, N. Guo, Y. Jia, H. You, CrystEngComm 2011, 13, 1786.

[34] C. C. R. Sutton, G. da Silva, G. V. Franks, Chem. - A Eur. J. 2015, 21, 6801-6805.

[35] Q.-D. Liu, J.-R. Li, S. Gao, B.-Q. Ma, F.-H. Liao, Q.-Z. Zhou, K.-B. Yu, Inorg. Chem. 
Commun. 2001, 4, 301-304.

[36] T. Devic, V. Wagner, N. Guillou, A. Vimont, M. Haouas, M. Pascolini, C. Serre, J. Marrot, M. Daturi, F. Taulelle, G. Férey, Microporous Mesoporous Mater. 2011, 140, 25-33.

[37] L. J. Charbonniere, N. Hildebrandt, R. F. Ziessel, H.-G. Loehmannsroeben, J. Am. Chem. Soc. 2006, 128, 12800-12809.

[38] H.-Y. D. Ke, E. R. Birnbaum, J. Lumin. 1995, 63, 9-17.

[39] A. N. Carneiro Neto, R. T. Moura, A. Shyichuk, V. Paterlini, F. Piccinelli, M. Bettinelli, O. L. Malta, J. Phys. Chem. C 2020, 10, DOI 10.1021/acs.jpcc.0c00759.

[40] J. Yang, X. Wang, L. Song, N. Luo, J. Dong, S. Gan, L. Zou, Opt. Mater. (Amst). 2018, 85, 71-78.

[41] Y. Zhang, J. Zhang, X. Li, X. Jiang, J. Shi, Y. Wen, J. Mater. Sci. Mater. Electron. 2018, 29, 3120-3126.

[42] T. Li, P. Li, Z. Wang, S. Xu, Q. Bai, Z. Yang, Dalt. Trans. 2015, 44, 16840-16846.

[43] V. Petricek, M. Dusek, L. Palatinus, 2006.

[44] J. F. Bérar, P. Lelann, J. Appl. Crystallogr. 1991, 24, 1-5.

[45] M. Sheldrick, G., Göttingen University, 1986.

[46] M. Sheldrick, G., Göttingen University, 1997.

[47] I. D. Brown, D. Altermatt, Acta Crystallogr. Sect. B 1985, 41, 244-247. 
[48] N. E. Brese, M. O’Keeffe, Acta Crystallogr. Sect. B 1991, 47, 192-197.

[49] W. Liu, H. H. Thorp, Inorg. Chem. 1993, 32, 4102-4105.

[50] L. Spek, A., Utrecht University, 2002. 